\title{
RETRIEVAL OF AEROSOL MICROPHYSICAL PROPERTIES BASED ON THE OPTIMAL ESTIMATION METHOD: INFORMATION CONTENT ANALYSIS FOR SATELLITE POLARIMETRIC REMOTE SENSING MEASUREMENTS
}

\author{
W. Z. Hou, Z. Q. Li*, F. X. Zheng, L. L. Qie \\ State Environment Protection Key Laboratory of Satellite Remote Sensing, Institute of Remote Sensing and Digital Earth, Chinese \\ Academy of Sciences, Beijing 100101, China - (houwz, lizq, zhengfx, qiell)@radi.ac.cn
}

KEY WORDS: Polarimetric Remote Sensing, Information Content Analysis, Aerosol Microphysical Properties, Optimal Estimation, Multispectral Reconstruction

\begin{abstract}
:
This paper evaluates the information content for the retrieval of key aerosol microphysical and surface properties for multispectral single-viewing satellite polarimetric measurements cantered at 410, 443, 555, 670, 865, 1610 and $2250 \mathrm{~nm}$ over bright land. To conduct the information content analysis, the synthetic data are simulated by the Unified Linearized Vector Radiative Transfer Model (UNLVTM) with the intensity and polarization together over bare soil surface for various scenarios. Following the optimal estimation theory, a principal component analysis method is employed to reconstruct the multispectral surface reflectance from $410 \mathrm{~nm}$ to $2250 \mathrm{~nm}$, and then integrated with a linear one-parametric BPDF model to represent the contribution of polarized surface reflectance, thus further to decouple the surface-atmosphere contribution from the TOA measurements. Focusing on two different aerosol models with the aerosol optical depth equal to 0.8 at 550nm, the total DFS and DFS component of each retrieval aerosol and surface parameter are analysed. The DFS results show that the key aerosol microphysical properties, such as the fine- and coarse-mode columnar volume concentration, the effective radius and the real part of complex refractive index at $550 \mathrm{~nm}$, could be well retrieved with the surface parameters simultaneously over bare soil surface type. The findings of this study can provide the guidance to the inversion algorithm development over bright surface land by taking full use of the single-viewing satellite polarimetric measurements.
\end{abstract}

\section{INTRODUCTION}

Retrieval of aerosol properties from the air-borne and spaceborne polarimetric measurements have received rapidly increased attention in recent years. While past studies have shown that polarimetric measurements contain abundant information for aerosol microphysical properties, most of these studies employed measurements of polarization either in the visible or close to the visible spectrum (Deuzé et al., 2001). However, polarization data in near infrared (NIR) or short-wave infrared (SWIR) wavelength bands (beyond $1.0 \mu \mathrm{m}$ ) have not yet been widely measured nor utilized for aerosol retrieval. Previous studies have shown that aerosol information content can be improved significantly with the use of measurements from more wavelengths and viewing angles (Mishchenko et al., 2007).

As a new polarimeter designed for the preparation of newgeneration of Polarization and Directionality of the Earth's Reflectance (POLDER) instrument and the airborne experiment of micropolarimeter (MICROPOL), the Multi-Viewing-ChannelPolarization Imager (3MI) employed 2 NIR polarized channels centered at 1.6 and $2.2 \mu \mathrm{m}$ and has been shown to have the advantages of simultaneous inversion of multiple aerosol parameters (Waquet et al., 2007). Besides, other new developed instruments include the research about airborne Research Scanning Polarimeter (RSP) and Airborne Multiangle SpectroPolarimetric Imager (AirMSPI) (Waquet et al., 2009; Xu et al., 2017), as well as the space borne Aerosol Polarimetry Sensor (APS) (Wu et al., 2015). Recently, a new space-borne instrument called Polarized Scanning Atmospheric Corrector (PSAC) has been also developed in Anhui Institute of Optics and Fine Mechanics, Chinese Academy of Sciences in China. The PSAC polarimeter is designed with multispectral single-viewing polarimetric measurements with $410,443,555,670,865,1610$ and $2250 \mathrm{~nm}$, aiming to provide the aerosol properties for atmospheric correction for other sensors onboard the same satellite platform. Besides, the airborne Advanced Atmosphere Multi-angle Polarization Radiometer (AMPR) has flown some experiments for aerosol retrieval tests (Wang et al., 2017).

This study evaluates the information content for the retrieval of aerosol microphysical and surface properties from a singleviewing satellite polarimetric measurements with the intensity and polarization together over bare soil surface. For information content analysis, the averaging kernel matrix is introduced to characterize the changes in the retrieved stated vector to changes in the true state vector, and the trace of this matrix is equivalent to the number of independent pieces of information from the topof-atmosphere (TOA) measurements, also called the degree of freedom for signal (DFS) (Frankenberg et al., 2012; Xu \& Wang, 2015; Chen et al., 2017). In this way, DFS is used to quantitatively represent the number of aerosol and surface parameters that can be retrieved independently from TOA radiance and polarization measurements, provided that the prior errors of retrieval parameters are characterized.

Unified Linearized Vector Radiative Transfer Model (UNLVRTM) is employed as the forward model for the simulations of TOA stokes vector and corresponding sensitivities (Wang et al., 2014), which are generated by the integration of surface reflectance and surface polarized contribution together for various scenarios with different aerosol models, observation geometries over bare soil surface. Based on the optimal estimation (OE) theory and the theoretical framework for aerosol optimized retrieval (Rodgers, 2000; Dubovik et al., 2011), the principal component analysis (PCA) method is used to

\footnotetext{
* Corresponding author
} 
reconstruct the multispectral surface reflectance by the four principal components (PCs) extracted from the ASTER spectral library (Baldridge et al., 2009), and thus the weighting coefficient of each PC could be retrieved instead of the direct retrieval of surface reflectance (Hou et al., 2016, 2017). Besides, a bidirectional polarized reflectance distribution function (BPDF) is used together to describe the surface polarized contribution, with assumption that the surface-polarized reflectance can be regarded as independent on the wavelength, in which the normalized difference vegetation index (NDVI) for the BPDF model could be determined by the surface reflectance at 670 and 865nm (Maignan et al., 2009; Litvinov et al., 2011).

In this study, we briefly describe the model and method in section 2 to present our approach and experiment designs for the simulation of measurements. Subsequently, we conduct the analysis of information content for retrieved aerosol and surface parameters based on these synthetic measurements in section 3 , and finally give the conclusions in section 4 .

\section{MODEL AND METHOD}

\subsection{Optimal Estimation and Information Content Theory}

Based on the OE theory (Rodgers, 2000), the forward model usually can be defined in the form as

$$
\mathbf{y}=\mathbf{F}(\mathbf{x})+\boldsymbol{\epsilon},
$$

where $\mathbf{x}$ represents a state vector to be retrieved, $\mathbf{y}$ represents an observation vector, $\mathbf{F}$ mans a forward model and corresponds to UNL-VRTM in this study, and $\boldsymbol{\epsilon}$ is an experimental error term that includes observation noise and forward model uncertainty.

For the OE inversion, the scalar-valued cost function $J(\mathbf{x})$ can be written as

$J(\mathbf{x})=$

$\frac{1}{2}[\mathbf{y}-\mathbf{F}(\mathbf{x})]^{T} \mathbf{S}_{\epsilon}^{-1}[\mathbf{y}-\mathbf{F}(\mathbf{x})]+\frac{1}{2}\left(\mathbf{x}-\mathbf{x}_{\mathrm{a}}\right)^{T} \mathbf{S}_{\mathrm{a}}^{-1}\left(\mathbf{x}-\mathbf{x}_{\mathrm{a}}\right)$,

Where the superscript $T$ and -1 represent the transpose and inverse operation of matrix respectively. $\mathbf{S}_{\epsilon}$ means the covariance matrix of the error from both the measurements and the forward model, $\mathbf{S}_{\mathrm{a}}$ means the error covariance matrix of the a priori estimate $\mathbf{x}_{\mathrm{a}}$. Correspondingly, we have the gradient vector as

$$
\nabla_{\mathbf{x}} J(\mathbf{x})=-\mathbf{K}^{T} \mathbf{S}_{\epsilon}^{-1}[\mathbf{y}-\mathbf{F}(\mathbf{x})]+\mathbf{S}_{\mathrm{a}}^{-1}\left(\mathbf{x}-\mathbf{x}_{\mathrm{a}}\right),
$$

in which, the Jacobians matrix $\mathbf{K}$ represent the partial derivatives of $\mathbf{F}(\mathbf{x})$ with respect to $\mathbf{x}$ with the corresponding element as

$$
\mathbf{K}_{j, i}=\frac{\partial y_{j}}{\partial x_{i}},(i=1, \cdots n ; j=1, \cdots, m) .
$$

In order to solve the optimizated inversion model, the inversion problem can be as a nonlinear optimization problem as

$$
\begin{aligned}
& \min J(\mathbf{x}) \\
& \text { s.t. } \mathbf{l} \leq \mathbf{x} \leq \mathbf{u},
\end{aligned}
$$

in which $\mathbf{I}$ and $\mathbf{u}$ mean the lower and upper bounds for the retrieval parameter vector $\mathbf{x}$, respectively. When the optimal iteration of Quasi-Newton converges under the condition of predefined convergence accuracy, the retrieved stated vector $\hat{\mathbf{x}}$ could be obtained (Byrd et al., 1995; Yu et al., 2014).

For information content analysis, the averaging kernel matrix can be represented in the form as

$$
\frac{\partial \hat{\mathbf{x}}}{\partial \mathbf{x}}=\mathbf{A}=\left(\mathbf{K}^{T} \mathbf{S}_{\epsilon}^{-1} \mathbf{K}+\mathbf{S}_{\mathrm{a}}^{-1}\right)^{-1} \mathbf{K}^{T} \mathbf{S}_{\epsilon}^{-1} \mathbf{K} .
$$

Correspondingly, the DFS of each individual retrieved parameter can be represented by

$$
\mathrm{DFS}=\frac{\partial y_{j}}{\partial x_{i}}=\mathbf{A}_{i, i},
$$

and the total DFS could be calculated by $\sum_{i=1}^{n} \mathbf{A}_{i, i}$. The values of $\mathbf{A}_{i, i}$ are in the range of 0 and 1 , in which the DFS result $\mathbf{A}_{i, i}=1$ means that the observation is able to fully characterize the truth of $\mathrm{x}_{i}$; by contrast, $\mathbf{A}_{i, i}=0$ means that the observation do not contain any information on $\mathrm{x}_{i}$ at all. The closer the value of $\mathbf{A}_{i, i}$ to 1 , the better the retrieval of parameter $\mathrm{x}_{i}$. Besides, as long as the DFS result $\mathbf{A}_{i, i}>0.5$, we assume that the retrieval of parameter $\mathrm{x}_{i}$ could be carried out (Hou et al., 2018).

\subsection{Forward Simulations of Polarimetric Measurements}

As the forward model for the simulation of synthetic measurements in this paper, UNL-VRTM was specifically designed for the simulation of atmospheric remote sensing observations and for the inversion of aerosol, gas, cloud, and/or surface properties from these observations (Xu et al., 2017). The structure of UNL-VRTM includes the VLIDORT for radiative transfer (Sprr et al., 2006), a linearized Mie and a linearized TMatrix code for aerosol single scattering, a Rayleigh scattering module, and line-by-line gas absorption calculation with HITRAN database, as well as a surface bidirectional reflectance distribution function (BRDF) and bidirectional polarized reflectance distribution function (BPDF) module respectively for characterizing the surface properties. UNL-VRTM not only simulated the full elements of the Stokes vector, but also calculated their sensitivities (Jacobians) with respect to various parameters relevant to aerosol microphysics, optical parameters and surface properties (Wang et al., 2014).

Based on the wavelength bands setting of PSAC instrument for aerosol detecting, measurement vector $\mathbf{y}$ can be defined as

$$
\mathbf{y}=\left[I_{\lambda_{1}}, \cdots, I_{\lambda_{7}}, Q_{\lambda_{1}}, \cdots, Q_{\lambda_{7}}, U_{\lambda_{1}}, \cdots, U_{\lambda_{7}}\right]^{T},
$$

in which, $\lambda_{1}-\lambda_{7}$ are used to note the wavelength band 410,443 , $555,670,865,1610,2250 \mathrm{~nm}$ respectively. By considering the integrated effects of instrumental noise with radiometric calibration and polarimetric accuracy uncertainties, the errors of measurement are all set to $5 \%$ for both the intensity and the polarization for the information content analysis.

For the aerosol model setting, the bimodal lognormal function is selected to describe the particle size distribution of spherical aerosol particles, and this paper characterizes aerosol properties with five pairs of parameters for both fine and coarse mode aerosol particles, namely, the columnar volume concentration $V_{0}^{\mathrm{f}}$ and $V_{0}^{\mathrm{c}}$, the effective radius $r_{\mathrm{eff}}^{\mathrm{f}}$ and $r_{\mathrm{eff}}^{\mathrm{c}}$, the effective variance $v_{\text {eff }}^{\mathrm{f}}$ and $v_{\text {eff }}^{\mathrm{c}}$, the real and imaginary part of complex refractive index $m_{\mathrm{r}}^{\mathrm{f}}, m_{\mathrm{i}}^{\mathrm{f}}, m_{\mathrm{r}}^{\mathrm{c}}$ and $m_{\mathrm{i}}^{\mathrm{c}}$ at $550 \mathrm{~nm}$, where the superscript $\mathrm{f}$ and $\mathrm{c}$ represent the a fine and a coarse mode respectively.

For the surface reflectance model, the land surface reflectance matrix $\boldsymbol{R}$ is represent by the combination of surface reflection contribution by $r_{\lambda}$ and polarized contribution by $\rho_{\text {Maignan }} \mathbf{F}\left(\gamma, n_{i}\right)$, where $r_{\lambda}$ represent the Lambertian surface reflectance at the wavelength of $\lambda, \mathbf{F}\left(\gamma, n_{i}\right)$ means the Fresnel reflection matrix, $n_{i}$ is the reflective index of the vegetative matter, $\gamma$ means the half the phase angle, which is supplementary to the scattering angle (Dubovik et al., 2011). In addition, $\rho_{\text {Maignan }}$ represent the coefficient expression of BPDF model, and $C$ is the only free linear parameter of this wavelengthindependent model, which depends on the surface type (Maignan et al., 2009). For the bare soil surface, we set the $C=6.9$ with the NDVI $=0.03$ by following the work of Litvinov et al. (2011).

Following the work of Hou et al. (2016), the surface reflectance $r_{\lambda}$ could be decomposed into a weighted combination of PCs with the corresponding weighting coefficients in the form of

$$
r_{\lambda_{i}}=\sum_{j=1}^{m} P_{i, j} w_{i}+\varepsilon_{\lambda_{i}},(i=1, \cdots, d),
$$


where the $P_{i, j}$ means the element of each PC, and $w_{i}$ means the weighting coefficient. Besides, PCA results have shown that four $\mathrm{PCs}$ are enough to reconstruct the multispectral surface reflectance in seven wavelengths from $410 \mathrm{~nm}$ to $2250 \mathrm{~nm}$. Thus, the vector of weighting coefficients $\boldsymbol{w}=\left[w_{1}, w_{2}, w_{3}, w_{4}\right]^{T}$ could be used in the inversion framework instead of the retrieval of the surface reflectance at each wavelength.

\subsection{Definition of State Vector and A Priori Error}

For the information content analysis of the total DFS in the retrieval of aerosol and surface parameters, the state vector can be defined as

$\mathbf{x}=\left[V_{0}^{\mathrm{f}}, V_{0}^{\mathrm{c}}, m_{\mathrm{r}}^{\mathrm{f}}, m_{\mathrm{i}}^{\mathrm{f}}, m_{\mathrm{r}}^{\mathrm{c}}, m_{\mathrm{i}}^{\mathrm{c}}, r_{\mathrm{eff}}^{\mathrm{f}}, v_{\mathrm{eff}}^{\mathrm{f}}, r_{\mathrm{eff}}^{\mathrm{c}}, v_{\mathrm{eff}}^{\mathrm{c}}, w_{1}, w_{2}, w_{3}, w_{4}, C\right]^{T}$

which contain ten aerosol microphysical parameters, four weighting coefficients of surface reflectance and one BPDF parameters together. Here, we assume that the a priori errors in the aerosol and surface parameters are mutually independent of each other, and thus, the error matrix $\boldsymbol{S}_{\mathrm{a}}$ can be simplified as a diagonal matrix. Besides, the a priori errors in the weighting coefficients $\boldsymbol{w}$ correspond to the standard errors of the surface reflectance dataset for bare soil (Hou et al., 2016). In addition, the a priori error in the parameter $C$ of the BPDF, which are assumed to be $40 \%$ by following the work of Maignan et al. (2009).

Due to an insufficient number of single-angle observations, these ten aerosol parameters cannot be retrieved simultaneously with surface parameters; thus, we have to select some key parameters to separately retrieve fine- and coarse-dominated aerosols based on an analysis of their individual information contents. Accordingly, for fine-dominated aerosols, the state vector contains only six aerosol elements and five surface parameters as

$$
\mathbf{x}=\left[V_{0}^{\mathrm{f}}, V_{0}^{\mathrm{c}}, m_{\mathrm{r}}^{\mathrm{f}}, m_{\mathrm{i}}^{\mathrm{f}}, r_{\mathrm{eff}}^{\mathrm{f}}, r_{\mathrm{eff}}^{\mathrm{c}}, w_{1}, w_{2}, w_{3}, w_{4}, C\right]^{T} .
$$

Meanwhile, for the coarse-dominated aerosols, the state vector also includes

$$
\mathbf{x}=\left[V_{0}^{\mathrm{f}}, V_{0}^{\mathrm{c}}, m_{\mathrm{r}}^{\mathrm{c}}, m_{\mathrm{i}}^{\mathrm{c}}, r_{\mathrm{eff}}^{\mathrm{f}}, r_{\mathrm{eff}}^{\mathrm{c}}, w_{1}, w_{2}, w_{3}, w_{4}, C\right]^{T} .
$$

For the information contents using these selected aerosol parameters, the AERONET retrieval errors can be employed for the a priori errors in the predefined aerosol parameters (Dubovik et al., 2000), which are not contained within $\mathbf{x}$ but quantitatively influence the measurements in the forward model.

In addation, the setting of a priori errors of measurements, aerosol models and each retrieved parameter are same as the parameters setting in the work of Hou et al. $(2017,2018)$, thus the detailed results are not listed here due to space limitations.

\section{INFORMATON CONTENT ANALYSIS RESULTS}

\subsection{Synthetic Data}

To obtain the synthetic data of PSAC for the information content analysis, different observation geometries are considered with various solar zenith angles $\left(\theta_{0}=40^{\circ}\right)$, viewing zenith angles $\left(\theta_{\mathrm{v}}=0^{\circ}-60^{\circ}\right.$ with a step of $\left.5^{\circ}\right)$ and relative azimuth angles $\left(\phi=0^{\circ}-180^{\circ}\right.$ with a step of $\left.10^{\circ}\right)$. The TOA synthetic data are calculated using UNL-VRTM for a mid-latitude summer atmospheric profile for both fine-dominated and coarsedominated aerosol cases. In both cases, the aerosols are mixed with different relative percentages of fine- and coarse-mode particles, in which the fine-mode fraction of columnar volume concentration $\mathrm{FMF}_{V}$ corresponds to 0.8 and 0.2 , respectively. Besides, the parameters of particle size distribution and complex refractive index for both fine and coarse mode aerosols are taken from the work of Hou et al. $(2017,2018)$, based on the ground measurements of Sun-sky radiometer observation network (SONET) (Li et al., 2018). Figure 1 shows the scattering phase function $\left(P_{11}\right)$ and the polarized phase function $\left(-P_{12}\right)$ for the fine-mode and coarse-mode aerosol scenarios respectively. Specifically, we employ one typical AOD of 0.8 at $550 \mathrm{~nm}$ to represent the moderate polluted aerosol loadings, and thus the total columnar volume concentration $V_{0}$ can vary from 0.149 to $0.394 \mu \mathrm{m}^{3} \mu \mathrm{m}^{-2}$ with the corresponding $\mathrm{FMF}_{V}$ decreasing from 0.8 to 0.2 for the fine-dominated and coarse-dominated aerosol scenarios, respectively.

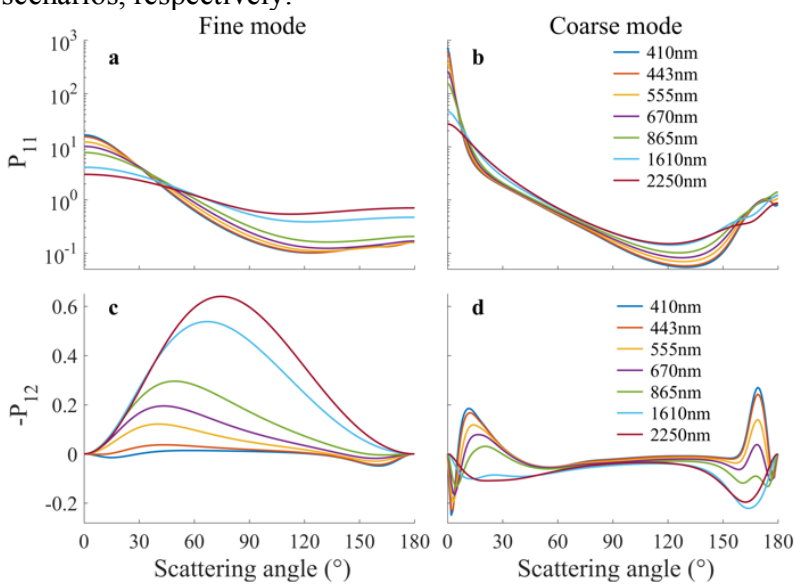

Figure 1. The scattering phase function $P_{11}(\mathrm{a}, \mathrm{b})$ and the polarized phase function $-P_{12}(\mathrm{c}, \mathrm{d})$ as functions of the scattering angles for fine- and coarse-mode aerosols at each wavelength adopted for the information content analysis

\subsection{Total DFS of Aerosol and Surface Retrieval}

Figure 2 shows the mean and standard deviation of total DFS of aerosol and surface parameters respectively, in which the results are calculated for the simultaneous retrieval of the ten aerosol parameters $\left(V_{0}^{\mathrm{f}}, V_{0}^{\mathrm{c}}, \mathrm{m}_{\mathrm{r}}^{\mathrm{f}}, m_{\mathrm{i}}^{\mathrm{f}}, m_{\mathrm{r}}^{\mathrm{c}}, m_{\mathrm{i}}^{\mathrm{c}}, r_{\mathrm{eff}}^{\mathrm{f}}, v_{\text {eff }}^{\mathrm{f}}, r_{\mathrm{eff}}^{\mathrm{c}}\right.$ and $\left.v_{\text {eff }}^{\mathrm{c}}\right)$ and five surface parameters $\left(w_{1}, w_{2}, w_{3}, w_{4}\right.$ and $\left.C\right)$ along the polar observation geometry $\left(\theta_{\mathrm{v}}=0^{\circ}-60^{\circ}\right.$ and $\left.\phi=0^{\circ}-180^{\circ}\right)$ as a histogram with error bars in consideration of 2 typical aerosol models for bare soil surface. Correspondingly, the mean total DFS of aerosol parameters are about 6 and 7 for the finedominated and coarse-dominated aerosols, while the mean total DFS of surface parameters are about 4 for both aerosol models.

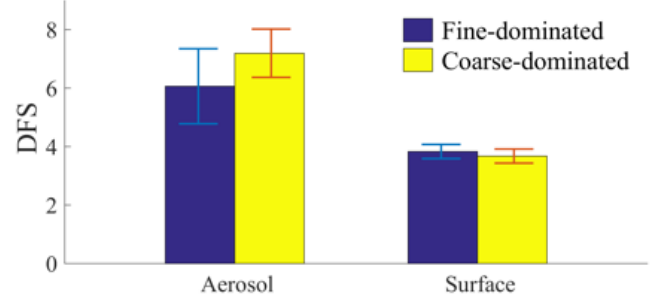

Figure 2. The mean and standard deviation of the total DFS presented in the format of a histogram with error bars for bare soil surface type.

To discuss the contribution from the information content to each retrieval parameter for the different scenarios, we investigate the information content for each parameter in the state vector in Eq. (10). Similar as Figure 2, Figure 3 further illustrates the mean and standard deviation of each DFS for the simultaneous retrieval of the ten aerosol parameters and five parameters together for fineand coarse-dominated aerosols respectively. In which, panels (a) corresponds to the results for aerosols parameters, and panels (b) 
plots the results for surface parameters separately. With the AOD $=0.8$ at $550 \mathrm{~nm}$, for the fine-dominated aerosols, the fine-mode parameters $V_{0}^{\mathrm{f}}, \mathrm{m}_{\mathrm{r}}^{\mathrm{f}}, m_{\mathrm{i}}^{\mathrm{f}}, r_{\text {eff }}^{\mathrm{f}}$ and $v_{\text {eff }}^{\mathrm{f}}$ could be well retrieved with the corresponding DFS $>0.75$; while for the coarse-dominated aerosols, both the fine-mode and coarse-mode parameters including $V_{0}^{\mathrm{f}}, V_{0}^{\mathrm{c}}, \mathrm{m}_{\mathrm{r}}^{\mathrm{f}}, m_{\mathrm{r}}^{\mathrm{c}}, r_{\text {eff }}^{\mathrm{f}}$ and $r_{\text {eff }}^{\mathrm{c}}$ could be well retrieved with the corresponding larger DFS.

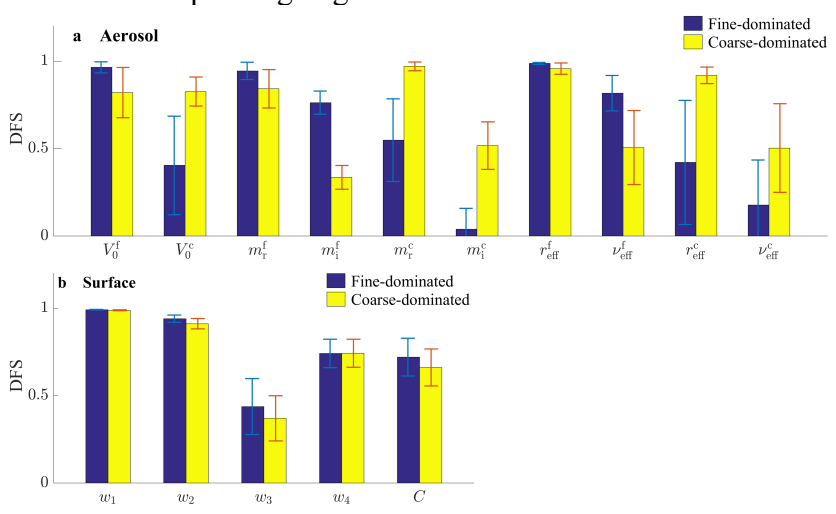

Figure 3. The mean and standard deviation of the each DFS component of aerosol (a) and surface parameters (b) presented in the format of a histogram with error bars.

\subsection{DFS of Selected Parameters}

Since these ten aerosol parameters could not be simultaneously retrieved with five surface parameters due to the insufficient information content, then we need to consider predefining some parameters with a priori errors to constrain the retrievals of other relatively important aerosol parameters, based on the analysis in section 3.2. Corresponding to the state vector elements in Eq. (11) and Eq. (12), we selected six aerosol parameters $\left(V_{0}^{\mathrm{f}}, V_{0}^{\mathrm{c}}, m_{\mathrm{r}}^{\mathrm{f}}\right.$, $m_{\mathrm{i}}^{\mathrm{f}}, r_{\mathrm{eff}}^{\mathrm{f}}$ and $\left.r_{\mathrm{eff}}^{\mathrm{c}}\right)$ for the retrieval of fine-dominated aerosols, and six aerosol parameters $\left(V_{0}^{\mathrm{f}}, V_{0}^{\mathrm{c}}, m_{\mathrm{r}}^{\mathrm{c}}, m_{\mathrm{i}}^{\mathrm{c}}, r_{\mathrm{eff}}^{\mathrm{f}}\right.$ and $\left.r_{\mathrm{eff}}^{\mathrm{c}}\right)$ for the retrieval of coarse-dominated aerosols.

Figure 4 illustrates the mean and standard deviation of the DFS values for the simultaneous retrieval of the six selected aerosol parameters with five surface parameters for the fine-dominated and the coarse-dominated aerosols respectively. Compared with the DFS shown in Figure 3, it is evident that the DFS of each selected parameter exhibits a significant improvement, and $V_{0}^{\mathrm{c}}$ also could be retrieved for fine-dominated aerosols. Although the weighting coefficient $w_{3}$ could not be retrieved due to the week information content, the multispectral surface reflectance of bare soil still could be well reconstructed with other 3 PCs, because the $3^{\text {rd }} \mathrm{PC}$ only account for less than $1 \%$ of the total variance contribution. In addition, the BPDF parameter $C$ could be also retrieved with the DFS are all larger than 0.5 , no matter for finedominated or coarse-dominated aerosols.

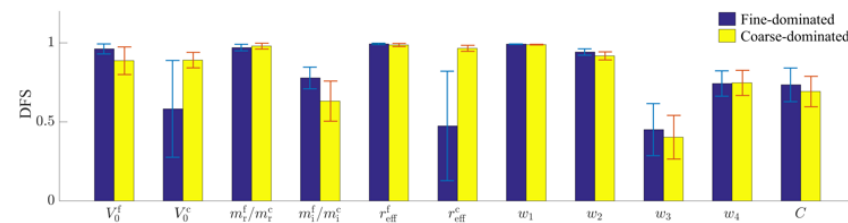

Figure 4. Same as Figure 3 but for six selected aerosol parameters and five surface parameters together based on the predefinition of other aerosol parameters with a priori errors. In which, the fine-mode $m_{\mathrm{r}}^{\mathrm{f}}$ and $m_{\mathrm{i}}^{\mathrm{f}}$ are selected for fine-dominated aerosols, while the coarse-mode $m_{\mathrm{r}}^{\mathrm{c}}$ and $m_{\mathrm{i}}^{\mathrm{c}}$ are selected for coarse-dominated aerosols.

\section{CONCLUSIONS}

Following the synthetic data simulated by UNL-VTM from the multispectral single-viewing measurements of the intensity and polarization together over bright bare soil surface for various scenarios, we conduct the information content analysis for aerosol microphysical and surface properties. To decouple the surface-atmosphere contribution from the TOA measurement, PCA method is used to reconstruct the multispectral surface reflectance in seven wavelengths from $410 \mathrm{~nm}$ to $2250 \mathrm{~nm}$. By this means, four weighting coefficients could be used in the inversion framework instead of the retrieval of the surface reflectance at each wavelength. While for the contribution of polarized surface reflectance, the linear one-parametric BPDF model is used in the inversion framework, and only one parameter $C$ need to be retrieved with the corresponding NDVI.

The DFS analysis in this study shows that some key aerosol microphysical properties could be retrieved with the surface parameters simultaneously, though over bright bare soil surface . For example, the fine-mode parameters $V_{0}^{\mathrm{f}}, \mathrm{m}_{\mathrm{r}}^{\mathrm{f}}, m_{\mathrm{i}}^{\mathrm{f}}, r_{\mathrm{eff}}^{\mathrm{f}}$ and $v_{\text {eff }}^{\mathrm{f}}$ could be well retrieved for the fine-dominated aerosols, while the parameters $V_{0}^{\mathrm{f}}, V_{0}^{\mathrm{c}}, \mathrm{m}_{\mathrm{r}}^{\mathrm{f}}, m_{\mathrm{r}}^{\mathrm{c}}, r_{\mathrm{eff}}^{\mathrm{f}}$ and $r_{\text {eff }}^{\mathrm{c}}$ could be well retrieved for the coarse-dominated aerosols. Besides, if six aerosol parameters $\left(V_{0}^{\mathrm{f}}, V_{0}^{\mathrm{c}}, m_{\mathrm{r}}^{\mathrm{f}}, m_{\mathrm{i}}^{\mathrm{f}}, r_{\mathrm{eff}}^{\mathrm{f}}\right.$ and $\left.r_{\mathrm{eff}}^{\mathrm{c}}\right)$ are selected for the retrieval with surface parameters, the $V_{0}^{\mathrm{c}}$ also could be retrieved for fine-dominated aerosols. In addition, based on the well retrieval of three weighting coefficient $\left(w_{1}, w_{2}\right.$ and $\left.w_{4}\right)$, the multispectral surface reflectance of bare soil still could be reconstructed and further retrieved. Moreover, the BPDF parameter $C$ could be also retrieved for both fine-dominated and coarse-dominated aerosols.

The findings of this study can provide important guidance to the algorithm development over bright surface land for the simultaneous retrieval of the aerosol key microphysical and surface properties, by taking full use of the multispectral polarimetric measurements with NIR and SWIR wavelength.

\section{ACKNOWLEDGEMENTS}

This study was supported by the Open Fund of State Key Laboratory of Remote Sensing Science (Grant No. OFSLRSS201710) and National Natural Science Foundation of China (Grant No. 41505022 and 41671367). Meanwhile, we acknowledge the UNL-VRTM codes developed by Prof. Jun Wang and Dr. Xiaoguang Xu in the University of Iowa. The codes used for simulations and information content analysis are available at the link of UNL-VRTM (www.unl-vrtm.com).

\section{REFERENCES}

Baldridge, A.M., Hook, S.J., Grove, C.I., Rivera, G., 2009. The ASTER spectral library version 2.0. Remote Sensing of Environment, 113, pp. 711-715.

Byrd, R., Lu, P., Nocedal, J., Zhu, C., 1995. A limited memory algorithm for bound constrained optimization. SIAM Journal on Scientific Computing, 16, pp. 1190-1208.

Chen, X., Wang, J., Liu, Y., Xu, X., Cai, Z., Yang, D., Yan, C.X., Feng, L., 2017. Angular dependence of aerosol information content in CAPI/TanSat observation over land: Effect of polarization and synergy with a-train satellites. Remote Sensing of Environment, 196, 163-177. 
Deuzé, J.L., Bréon, F.M., Devaux, C., Goloub, P., Herman, M., Lafrance, B., Maignan, F., Marchand, A., Nadal, F., Perry, G., Tanré, D, 2001. Remote sensing of aerosols over land surfaces from polder-adeos-1 polarized measurements. Journal of Geophysical Research, 106, pp. 4913-4926.

Dubovik, O., Smirnov, A., Holben, B.N., King, M.D., Kaufman, Y.J., Eck, T.F., Slutsker, I., 2000. Accuracy assessments of aerosol optical properties retrieved from aerosol robotic network (AERONET) sun and sky radiance measurements. Journal of Geophysical Research, 105, pp. 9791-9806.

Dubovik, O., Herman, M., Holdak, A., Lapyonok, T., Tanré, D., Deuzé, J.L., Ducos, F., Sinyuk, A., Lopatin, A., 2011. Statistically optimized inversion algorithm for enhanced retrieval of aerosol properties from spectral multi-angle polarimetric satellite observations. Atmospheric Measurement Techniques, 4, pp. 975-1018.

Frankenberg, C., Hasekamp, O., O'Dell, C., Sanghavi, S., Butz, A., Worden, J., 2012. Aerosol information content analysis of multi-angle high spectral resolution measurements and its benefit for high accuracy greenhouse gas retrievals. Atmospheric Measurement Techniques, 5, pp. 1809-1821.

Hou, W., Wang, J., Xu, X., Reid, J.S., Han, D., 2016. An algorithm for hyperspectral remote sensing of aerosols: 1 . Development of theoretical framework. Journal of Quantitative Spectroscopy and Radiative Transfer, 178, pp. 400-415.

Hou, W., Wang, J., Xu, X., Reid, J.S., 2017. An algorithm for hyperspectral remote sensing of aerosols: 2 . Information content analysis for aerosol parameters and principal components of surface spectra. Journal of Quantitative Spectroscopy and Radiative Transfer, 192, pp. 14-29.

Hou, W., Li, Z., Wang, J., Xu, X., Goloub, P., Qie, L., 2018. Improving remote sensing of aerosol microphysical properties by near-infrared polarimetric measurements over vegetated land: Information content analysis. Journal of Geophysical Research: Atmospheres, 123, pp. 2215-2243.

Li, Z., Xu, H., Li, K., Li, D., Xie, Y., Li, L., Zhang, Y., Gu, X., Zhao, W., Tian, Q., Deng, R., Su, X., Huang, B., Qiao, Y., Cui, W., Hu, Y., Gong, C., Wang, Y., Wang, X., Wang, J., Du, W., Pan, Z., Li, Z., Bu, D., 2018. Comprehensive study of optical, physical, chemical and radiative properties of total columnar atmospheric aerosols over china: An overview of sun-sky radiometer observation network (SONET) measurements. Bulletin of the American Meteorological Society, 99(4).

Litvinov, P., Hasekamp, O., Cairns, B., 2011. Models for surface reflection of radiance and polarized radiance: Comparison with airborne multi-angle photopolarimetric measurements and implications for modeling top-of-atmosphere measurements. Remote Sensing of Environment, 115, pp. 781-792.

Maignan, F., Bréon, F.-M., Fédèle, E., Bouvier, M., 2009. Polarized reflectances of natural surfaces: Spaceborne measurements and analytical modeling. Remote Sensing of Environment, 113, pp. 2642-2650.

Mishchenko, M.I., Cairns, B., Hansen, J.E., Travis, L.D., Kopp, G., Schueler, C.F., Fafaul, B.A., Hooker, R.J., Maring, H.B., Itchkawich, T., 2007. Accurate monitoring of terrestrial aerosols and total solar irradiance: Introducing the glory mission. Bulletin of the American Meteorological Society, 88, pp. 677-691.
Rodgers, C.D., 2000. Inverse methods for atmospheric sounding: Theory and practice. World Scientific, Singapore, pp. 13-40.

Spurr, R., 2006. Vlidort: A linearized pseudo-spherical vector discrete ordinate radiative transfer code for forward model and retrieval studies in multilayer multiple scattering media. Journal of Quantitative Spectroscopy and Radiative Transfer, 102, pp. 316-342.

Wang, H., Yang, L., Deng, A., Du, W., Liu, P., Sun, X., 2017. Remote sensing of aerosol optical depth using an airborne polarimeter over north china, Remote Sensing, 9(979), pp. 1-19.

Wang, J., Xu, X., Ding, S., Zeng, J., Spurr, R., Liu, X., Chance, K., Mishchenko, M., 2014. A numerical testbed for remote sensing of aerosols, and its demonstration for evaluating retrieval synergy from a geostationary satellite constellation of geo-cape and goes-r. Journal of Quantitative Spectroscopy \& Radiative Transfer, 146, pp. 510-528.

Waquet, F., Goloub, P., Deuzé, J.L., Léon, J.F., Auriol, F., Verwaerde, C., Balois, J.Y., François, P., 2007. Aerosol retrieval over land using a multiband polarimeter and comparison with path radiance method. Journal of Geophysical Research, 112, pp. D11214.

Waquet, F., Cairns, B., Knobelspiesse, K., Chowdhary, J., Travis, L.D., Schmid, B., Mishchenko, M.I., 2009. Polarimetric remote sensing of aerosols over land. Journal of Geophysical Research, 114, pp. D01206.

Wu, L., Hasekamp, O., van Diedenhoven, B., Cairns, B., 2015. Aerosol retrieval from multiangle, multispectral photopolarimetric measurements: Importance of spectral range and angular resolution. Atmospheric Measurement Techniques, 8, pp. 2625-2638.

Xu, F., van Harten, G., Diner, D.J., Kalashnikova, O.V., Seidel, F.C., Bruegge, C.J., Dubovik, O., 2017. Coupled retrieval of aerosol properties and land surface reflection using the airborne multiangle spectropolarimetric imager. Journal of Geophysical Research: Atmospheres, 122, pp. 7004-7026.

Xu, X., Wang, J., 2015. Retrieval of aerosol microphysical properties from aeronet photopolarimetric measurements: 1 . Information content analysis. Journal of Geophysical Research: Atmospheres, 120, pp. 7059-7078.

Xu, X., Wang, J., Zeng, J., Spurr, R., Liu, X., Dubovik, O., Li, L., Li, Z., Mishchenko, M.I., Siniuk, A., Holben, B. N., 2015. Retrieval of aerosol microphysical properties from aeronet photopolarimetric measurements: 2. A new research algorithm and case demonstration. Journal of Geophysical Research: Atmospheres, 120, pp. 7079-7098.

Xu, X., Wang, J., Wang, Y., Zeng, J., Torres, O., Yang, Y., Marshak, A., Reid, J., Miller, S., 2017. Passive remote sensing of altitude and optical depth of dust plumes using the oxygen a and b bands: First results from epic/dscovr at lagrange-1 point. Geophysical Research Letters, 44, pp. 7544-7554.

Yu, J., Li, M., Wang, Y., He, G., 2014. A decomposition method for large-scale box constrained optimization. Applied Mathematics and Computation, 231, pp. 9-15. 